\title{
EVALUATION OF THE FORMABILITY OF AI-ALLOY EN-AA 6000 T6
}

\author{
Alexander SCHREK, Alena BRUSILOVÁ, Pavol SEJČ, Marcela POKUSOVÁ \\ Slovak University of Technology in Bratislava, Bratislava, Slovak Republic, EU, \\ alexander.schrek@stuba.sk
}

https://doi.org/10.37904/metal.2020.3470

\begin{abstract}
At the beginning of the production of body parts from Al-alloy, there was a requirement to experimentally verify its suitability for their production. This alloy is characterized by a combination of various stress-deformation properties influencing the non-uniform plastic flow of the material, especially during deep drawing of complex shaped drawn parts. The properties evaluation of the analyzed material was focused on the experimental determination and comparison of the parameters with the parameters given by the producer. The experiments were supplemented by deep drawing tests of the drawn part under laboratory conditions. The magnitudes and courses of tensile and holding forces on the experimental tool and the magnitudes of deformations at individual drawn part points were evaluated. The experiments confirmed the suitability of the material for deep drawing. They also indicated the sensitivity of the material to the setting of process parameters - holding force and lubrication on the forming tool.
\end{abstract}

Keywords: Car framework, Al-alloy, stress-strain characteristics, formability, testing methods

\section{INTRODUCTION}

Aluminum alloys began to be used in car bodies in 30 s of the last century. The lower price of steel and the increasing requirements for strength and stiffness properties have caused that steel in the form of conventional, high-strength, but also tailor welded blanks become the most widely used material [1-3]. However, higher demands on weight reduction in the construction of car bodies create the need for applications of aluminum or magnesium alloys. These materials are used not only for external car body parts, but also for parts of the body construction - the car framework [4-6]. At present, body parts made of aluminium and magnesium alloys have been used in automobiles since the lower middle class. Some carmakers as Audi, Jaguar, Landrover and others already produce all-aluminum bodies with weight savings of 30 to $40 \%$. After the start of the new press shop operations, VW Slovakia focuses on the production of parts from Al-alloys for the entire concern. In connection with the start production of the new generation of the Audi Q7 car, a request arose for the analysis of the formability of the EN-AA 6000 T6 material supplied by Magna Steyr Graz, from which the car's front bonnet parts are made. In the analysis of the properties of Al-alloy, the stress-strain characteristics, part of the FLD diagram [6-7] and workpieces made using a laboratory tool were evaluated. The strain magnitude in selected points of the workpiece and the influence of the holding force on the formability resp. workpiece shape were evaluated [8-9].

\section{PROPERTIES OF AL-ALLOY 6XXX}

A sheet of AIMgSi alloy with the designation EN-AA 6000 T6 and chemical composition (Table 1) was selected for the experiments. In 6xxx series alloys, the Mg2Si phase may be formed during the alloying of $\mathrm{Mg}$ and $\mathrm{Si}$, which results in their precipitation hardening. Alloys can be heat treated by solution annealing and subsequent natural aging (T4) or artificial aging (T6). 
Table 1 Chemical composition of aluminum alloy EN-AA 6000 T6 [10]

\begin{tabular}{|c|c|c|c|c|c|c|c|c|}
\hline $\mathbf{S i}$ & $\mathbf{F e}$ & $\mathbf{C u}$ & $\mathbf{M n}$ & $\mathbf{M g}$ & $\mathbf{C r}$ & $\mathbf{Z n}$ & $\mathbf{T i}$ & $\mathbf{A l}$ \\
\hline $0.5-1.5$ & $\leq 0.5$ & $\leq 0.25$ & $\leq 0.2$ & $0.25-0.8$ & $\leq 0.2$ & $\leq 0.2$ & $\leq 0.15$ & Rest \\
\hline
\end{tabular}

Mechanical properties according to the material standard were measured in the transverse direction to the rolling direction: Heat treatment T6 (artificial aging after solution annealing) at $185 \pm 2^{\circ} \mathrm{C}$ and $20 \pm 1$ min according to EN-515. Sheet thickness was $s \leq 2 \mathrm{~mm}, R_{\mathrm{p} 0.2} \geq 200 \mathrm{MPa}, R_{\mathrm{m}} \geq 240 \mathrm{MPa}, \mathrm{A}_{80} \geq 12 \%, 80 \mathrm{HBW} 2.5 / 62.5$ [10].

\section{EXPERIMENTS CONDITIONS}

The samples made of $1.1 \mathrm{~mm}$ thick aluminum alloy sheet according to STN EN ISO 6892-1.2010-01 were used for the static tensile test. A circular deformation mesh with a mean element diameter of $\phi 4.98 \mathrm{~mm}$ was screen-printed on the samples. The samples for the evaluation of the basic strength and deformation properties and anisotropy of the material were taken from the sheet in the direction $0^{\circ}, 45^{\circ}$ and $90^{\circ}$ with respect to the rolling direction. The tests were performed on an INSTRON 1195 test machine. The process was recorded with a Canon EOS1000D digital camera with a Canon EF-S $60 \mathrm{~mm}$ f2.8 Macro USM lens. The measured values of stress at yield strength $R_{p 0.2}=151.28 \mathrm{MPa}$ and at tensile

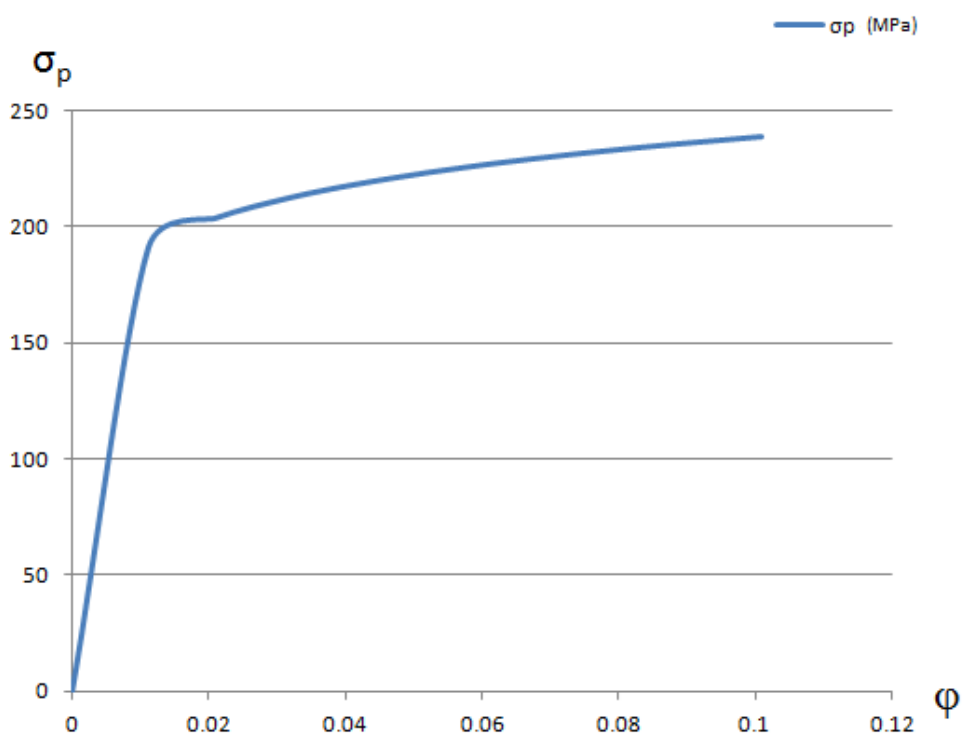
strength $R_{m}=215.73 \mathrm{MPa}$ reach slightly lower values than prescribed by the producer in the material standard, elongation $A_{80}=13.50 \%$ exceeds the prescribed values of the producer. The value of contraction $Z=40.76 \%$ is not stated in the material standard. The flow curve from the measured and calculated values is shown in Figure 1.

The strain hardening exponent was determined from the flow curve (Figure 1) and the parameters $\sigma_{\mathrm{A}}, \varphi_{\mathrm{A}}$ and $\sigma_{B}, \varphi_{B}$ according to equation (1):

$n=\frac{\log \sigma_{B}-\log \sigma_{A}}{\log \phi_{B}-\log \phi_{A}}=\frac{\log { }_{B} 238.655-\log 203.686}{\log 0.101-\log 0.021}=0.1009$

\section{MEASUREMENT OF NORMAL ANISOTROPY OF AL-ALLOY EN-AA 6000 T6}

Normal anisotropy values were determined by measuring the true strains of the test specimens from the deformation mesh photographs imported into the CATIA V5R20 program. The anisotropy values were registered in a static tensile test on sheet metal samples with orientation in the direction $0^{\circ}, 45^{\circ}$ and $90^{\circ}$ to he direction of rolling. In the images, 8 primary (in the direction of the action of drawing force) and secondary (in the direction perpendicular to the action of drawing force) axes of the formed ellipses were dimensioned (Figure 2). From the measured values of the individual elements of the deformation mesh, the values of the real dimensions and the values of the true strains were calculated by means of a scale. 


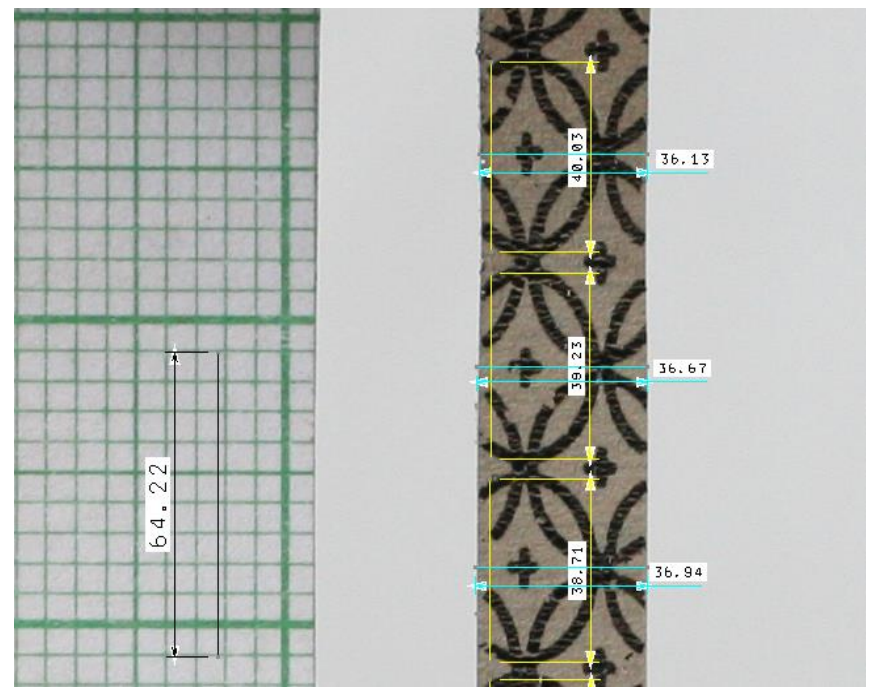

Figure 2 Method of measuring strains on samples in the CATIA V5R20 program

From the values of the strains, the average values of normal anisotropy were calculated:

$r_{0} \cdot=\frac{\phi_{2}}{\phi_{3}}=\frac{-0.0900}{-0.0782}=1.15$

$r_{45^{\prime}}=\frac{\phi_{2}}{\phi_{3}}=\frac{-0.0670}{-\log 0.1404}=0.48$

$r_{90^{\prime}}=\frac{\phi_{2}}{\phi_{3}}=\frac{-0.0757}{-\log 0.1185}=0.64$

and the mean value of normal anisotropy:

$r_{S}=\frac{1}{4}\left(r_{0} \cdot+2 . r_{45^{\prime}}+r_{90^{\circ}}\right)=\frac{1}{4}(1.1498+2.0 .4774+0.6392)=0.6686$

The normal anisotropy of samples oriented in the $0^{\circ}$ direction reached values greater than 1 . This means that the material is more prone to strain in the width and length directions than the thickness. For directions $45^{\circ}$ and $90^{\circ}$, the material is more prone to strain $\mathrm{n}$ the thickness direction.

\section{MEASUREMENT OF PLANAR ANISOTROPY OF ALUMINUM ALLOY EN-AA 6000 T6}

The samples oriented in the $0^{\circ}, 45^{\circ}$ and $90^{\circ}$ direction with respect to the rolling direction were subjected to a static tensile test on an Inspect 5 Desk device connected to a computer. The course of forces depending on the elongation of the sample was recorded in digital form in the LabMaster program.

Table 2 Values of anisotropies of stress-deformation properties

\begin{tabular}{|c|c|c|c|c|c|c|c|c|c|}
\hline & $1.0^{\circ}$ & 2. $0^{\circ}$ & $\varnothing 0^{\circ}$ & 3. $90^{\circ}$ & 4. $90^{\circ}$ & $\varnothing 90^{\circ}$ & $5.45^{\circ}$ & $6.45^{\circ}$ & $\varnothing 45^{\circ}$ \\
\hline $\mathbf{R}_{\mathbf{m}}$ & 268.65 & 255.51 & 262.08 & 238.13 & 251.80 & 244.96 & 274.64 & 264.86 & 269.75 \\
\hline$A_{R m}$ & & & & & & $-6.53 \%$ & & & $2.93 \%$ \\
\hline $\mathbf{R}_{\mathbf{p 0 , 2}}$ & 164.74 & 146.40 & 155.57 & 137.26 & 149.77 & 143.51 & 171.01 & 160.67 & 165.84 \\
\hline$A_{R p 0,2}$ & & & & & & $-7.75 \%$ & & & $6.60 \%$ \\
\hline$A_{80}$ & $25.08 \%$ & $23.55 \%$ & $24.32 \%$ & $22.04 \%$ & $23.96 \%$ & $23.00 \%$ & $24.84 \%$ & $25.12 \%$ & $24.98 \%$ \\
\hline$A_{A 80}$ & & & & & & $-5.41 \%$ & & & $2.73 \%$ \\
\hline $\mathbf{z}$ & $26.51 \%$ & $39.62 \%$ & $33.07 \%$ & $31.17 \%$ & $32.37 \%$ & $31.77 \%$ & $30.20 \%$ & $36.74 \%$ & $33.47 \%$ \\
\hline$A z$ & & & & & & $-3.91 \%$ & & & $1.22 \%$ \\
\hline
\end{tabular}


The values of anisotropies of stress-deformation properties reached values lower than $8 \%$ (Table 2). The values of mechanical properties corresponded to the material standard from the producer, but the nominal yield strength reached slightly lower values.

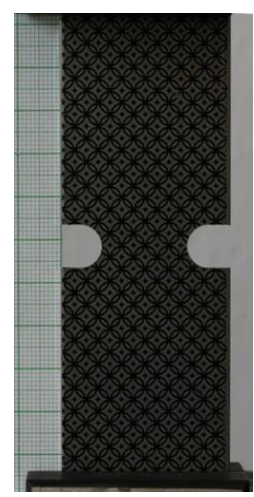

$\mathrm{R}=5$

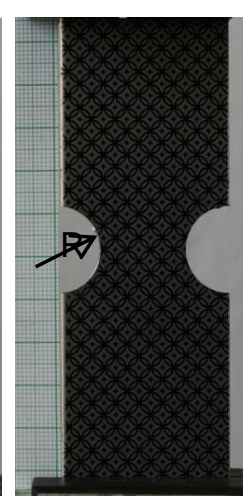

$\mathrm{R}=10$

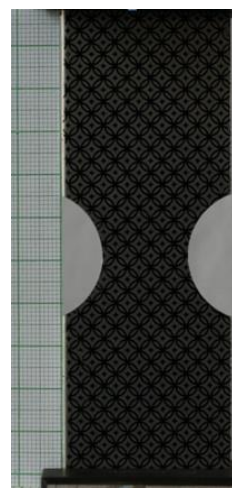

$\mathrm{R}=15$

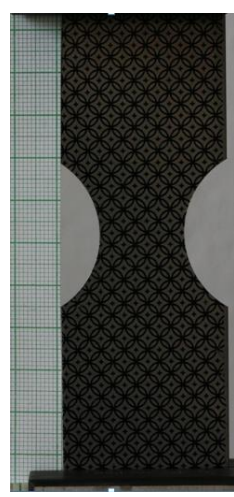

$\mathrm{R}=20$

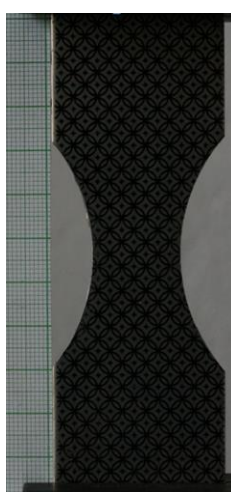

$\mathrm{R}=40$

Figure 3 Samples for determining part of the Forming Limit Diagram (FLD)
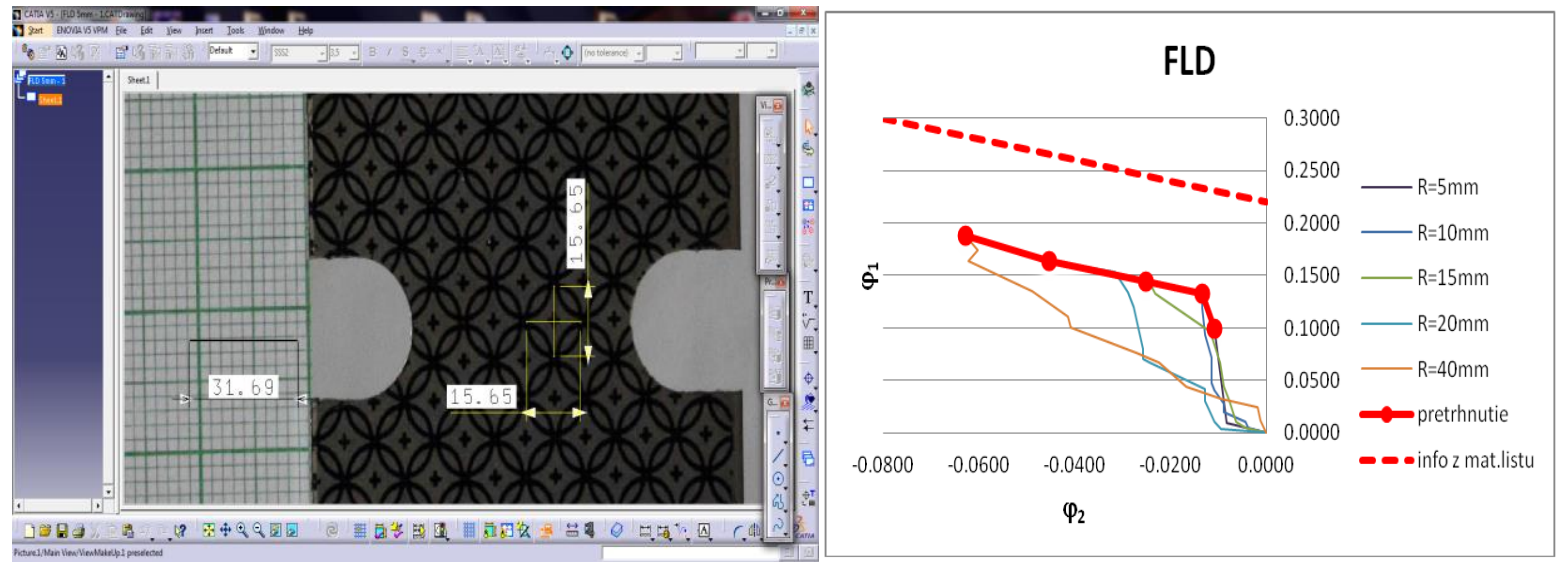

Figure 4 Deformation element measurement for a sample with $\mathrm{R}=5 \mathrm{~mm}$ (left), Part of the FLD for Al-alloy

EN-AA 6000 T6 (right)

\section{FORMING LIMIT DIAGRAM (FLD) OF ALUMINUM ALLOY EN-AA 6000 T6}

Circular cut samples with different cutout radius were used to determine a part of the forming limit $\mathrm{n}$ diagram (Figure 3). The time course of deformation of the circular elements of the deformation mesh was registered by a photographic device. The specimens were clamped in the jaws of the testing machine INSTRON 1195 so that the axis of the specimen was equally oriented with the axis of the applied force. During the experiment, images of the mesh deformation until their rupture were in sequence recorded. Images were imported into CATIA V5R20 software. The sizes of the primary and secondary axis of the resulting ellipse closest to the rupture point of the sample were measured. Dimensions were positioned so that the beginning and end of the dimension was located in the center of the ellipse line. To determine the real dimensions, a scale from graph paper was used for the conversion (Figure 4 left).

From the calculated strains values

$\phi_{1}=\ln \frac{a}{d}$

$\phi_{2}=\ln \frac{b}{d}$

a part of the Forming Limit Diagram (Figure 4 right) was constructed, which was used in another experiment to analysis the strains in most exposed parts of the drawn part. 


\section{DEFORMATION MEASUREMENT ON EN-AA 6000 T6 ALUMINUM ALLOY DRAWN PARTS}

The blanks for the deep-drawing experiment had a shape optimized by the Dynaform simulation program. They were made of aluminum alloy sheet type EN-AA 6000 T6 with a thickness of $1.1 \mathrm{~mm}$ and applied by deformation mesh by screen printing. The blanks were oriented so that the rolling direction formed an angle of $0^{\circ}, 45^{\circ}$ and $90^{\circ}$ with the major axis of the ellipse. They marked as follows: samples No.2 and 3 for $45^{\circ}$, samples No. 4 and 5 for $0^{\circ}$ and samples No.6 and 7 for- $90^{\circ}$. The drawing of the samples was performed on a doubleacting hydraulic press PYE $160 \mathrm{~S}$. The die of the tool was clamped on the ram press, the punch was placed on the press table. The force on the blankholder was adjustable by eight posts with a piezoelectric force transducer on every second column that was connected to the measuring device SPIDER 8 . The calibration stroke was performed empty and served to set a constant value of the holding force. WEDOLIT N22-3N lubricating oil was used to lubricate the functional parts. CATIA V5R20 software was used to measure the deformation of individual circles of the deformation mesh. The drawn parts images were taken with a Canon EOS-1000D camera with Canon EF-S 60mm f2.8 Macro USM lens. Sample No. 7 was selected, which was evaluated in the longitudinal, transverse and diagonal directions. The largest and smallest values of the ears in the corners of the drawn part were measured. The strain diagram was constructed from the measured and calculated strains values of individual elements of the deformation mesh (Figure 5).

a)
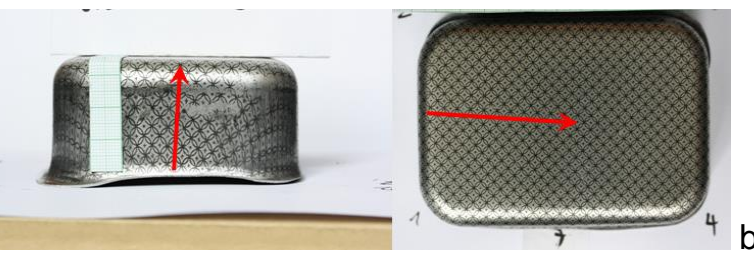

b)
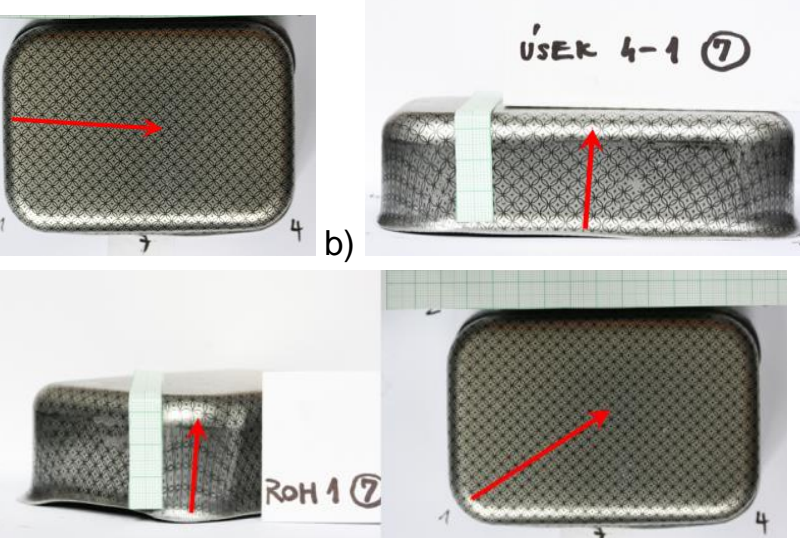

c)

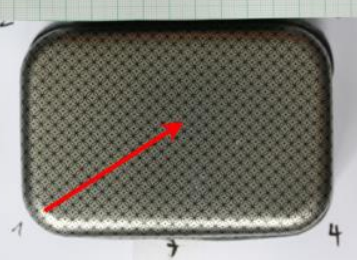

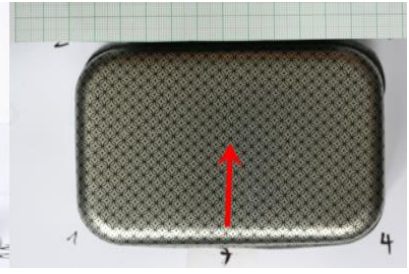

Figure 5 Measurement directions of strains on drawn parts: a) longitudinal direction, b) transverse direction, c) diagonal direction
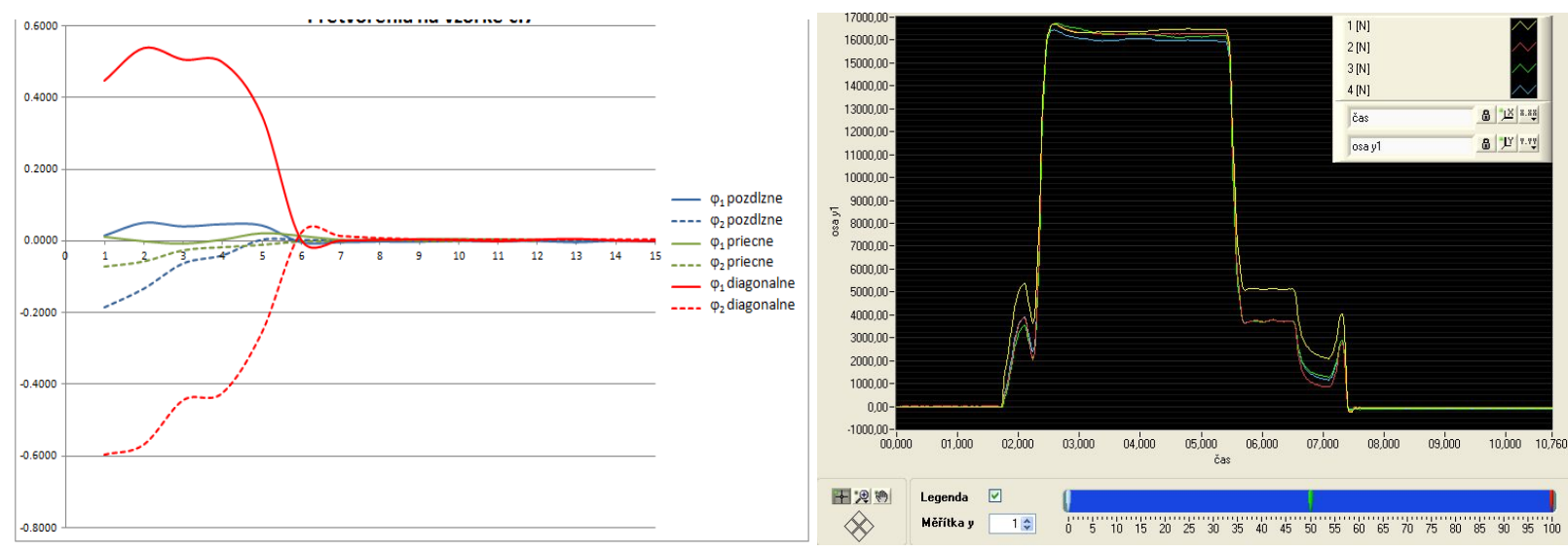

Figure 6 Graphical illustration of strains of the deformation mesh elements of sample No. 7 from the left edge to the center of the drawn part (left)), The course and magnitude of the holding forces depending on the stroke time during the calibration stroke (right) 
It was found that there is almost no or only minimal deformation at the bottom of the drawn parts (the face of the punch wasn't lubricated). Significant deformations were noticed on the side walls of the drawn parts. The largest deformations were measured in the corners of the drawn parts.

\section{MEASUREMENT OF HOLDING FORCES DURING DEEP DRAWING OF ALUMINUM ALLOY EN- AA-6000-T6}

Deep drawing of the drawn parts was performed on 6 samples according to the procedure described in the previous chapter. The result of the calibration of the force transducers is shown in Figure 6 . The transducers were connected to the measuring device SPIDER 8. Due to the shape of the drawn part, they were marked and arranged as follows: Sensor No.1 between corners No.2 and 3, Sensor No.2 between corners No.3 and 4, Sensor No.3 between corners No.4 and 1, Sensor No.4 between corners 1 and 2. In addition to the holding forces, the course of the total tensile force was also recorded on the sample No. 7 (Figure 7- curve 0). The most significant ear was formed in the corner No. 3, therefore the sample was also selected for measuring the deformation mesh strains.
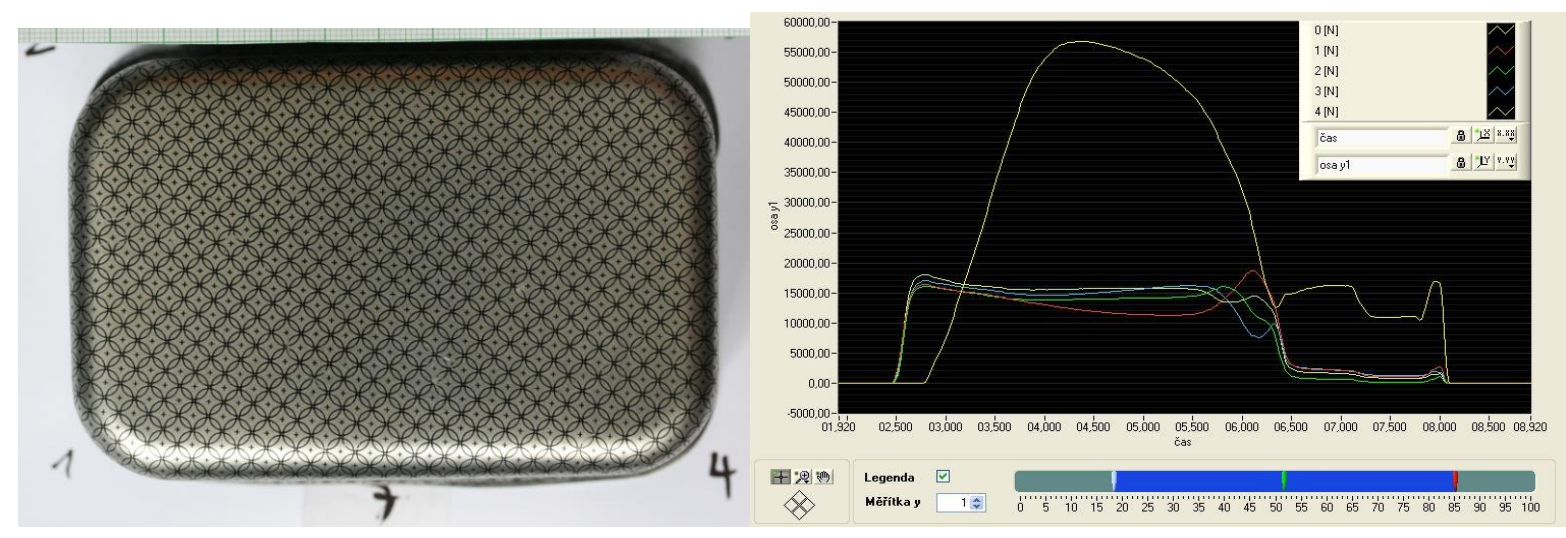

Figure 7 Magnitude and course of drawing and holding forces (workpiece No. 7)

\section{DISCUSSION OF RESULTS AND CONCLUSION}

The aim of the study was to analyze and evaluate the properties of a sheet $1.1 \mathrm{~mm}$ thick made of aluminum alloy EN-AA 6000 T6 designed for pressing the front hood of the car Audi Q7. The application of the deformation mesh to the test specimens and blanks as well as the use of a photogrammetric method of measuring the changes in the dimensions of the deformation mesh allowed to determine the size of the strains. A high-resolution camera using a MACRO function lens was used. The images were measured in the CAD program CATIA V5R20. The values of yield strength and tensile strength were lower, the measured elongation was higher.) The material sheet wasn't listed the value of contraction. The flow curve was used to determine the average value of the exponent of strain hardening, which was also not given in the material standard. The normal anisotropy values of the samples oriented in the $0^{\circ}$ direction reached values greater than 1 , i.e. the material is more prone to strain in the width direction than the thickness. In this direction, it should be realized the largest strains because there is no danger of critical thinning of the drawn part wall. In view of this fact, the shape of the blank should also be oriented. In the $45^{\circ}$ and $90^{\circ}$ directions, the material is more prone to strain in the thickness direction. Planar anisotropy showed a value bellow $8 \%$. The basic stress-strain properties differed only slightly and therefore there was no danger of significant ears formation during deep drawing. The measured results of part of the FLD diagram reached lower values in comparison to the producer's data. Measurements of the magnitudes and courses of the strains and holding forces showed the sensitivity of the sheet material to the quality and uniformity of lubrication of the tool functional parts. The resulting earing of the experimental drawn parts was caused by these drawbacks. Calibration of the holding forces and the design of 
the tool eliminates the asymmetry of the positioning of the blank at the beginning of the drawing process and the creation of conditions for the formation of undesired ears on the drawn part. The analysis showed a limited use of EN-AA 6000 T6 material for the production of car body parts, because the material showed limited plasticity and sensitivity to compliance with the process parameters of the production technology (distribution of holding force, lubrication).

\section{ACKNOWLEDGEMENTS}

This work was supported by the Slovak Research and Development Agency under the contract No.APVV-16-0485 and University Science Park STU Bratislava "ITMS code 26240220084. We would like to thank the Slovak grant agency VEGA for the financial support of the project VEGA 1/0405/19.

\section{REFERENCES}

[1] KINSEY, L. B., WU, X. Tailor-welded blanks for advanced manufacturing. Cambridge: Woodhead publishing, 2011. 208 p.

[2] EVIN, E., TOMÁŠ, M. Comparison of deformation properties of steel sheets for car body parts. Procedia Engineering. 2012, vol. 48, pp.115-122.

[3] EVIN, E. Design of dual phase high strength steels sheet for auto body. In $22^{\text {nd }}$ International Conference on Metallurgy and Materials - METAL 2013. Ostrava: Tanger, 2013.

[4] MERKLEIN, M., JOHANES, M., LECHNER, M., KUOERT, A. A review on tailored blanks - Production, applications and evaluation. Journal of Materials Processing Technology. 2014, vol. 214, pp. 151-164.

[5] SINHA, A.K., KIM, D.Y., CEGLAREK, D. Correlation analysis of the variation of weld seam and tensile strength in laser welding galvanized steel. Optics and Laser in Engineering. 2013, vol. 51, pp. 1143-1152.

[6] FRACZ, W., STACHOWICZ, F., TRZEPIECINSKI, T., PIEJA, T. Forming limit of the heat resistant AMS 5599 sheet metal. Hutnik-WH. 2014, vol. 81, No. 7, pp. 442-445.

[7] SLOTA, J., JURČIŠIN, M., SPIŠÁK, E. Experimental and numerical analysis of local mechanical properties of drawn part. Key Engineering Materials. 2014, vol. 586, pp. 245-248.

[8] REISGEN, U., SCHLESER, M., MOKROV, O., AHMED, E. Uni- and bi-axial deformation behavior of laser welded advanced high strength steel sheets. Journal of Materials Processing Technology. 2010, vol. 210, pp. 2188-2196.

[9] GROCHE, P., METZ, C. Investigation of active-elastic blank holder systems for high-pressure forming of metal sheets. International Journal of Machine Tools \& Manufacture. 2006, vol. 46, pp. 1271-1275. 